\title{
Risk is relative: Risk aversion yields cooperation rather than defection in cooperation-friendly environments
}

\author{
Andreas Glöckner • Benjamin E. Hilbig
}

Published online: 17 February 2012

(C) Psychonomic Society, Inc. 2012

\begin{abstract}
Previous findings concerning the relation of risk aversion and cooperation in repeated prisoner's dilemma games have been inconclusive. We hypothesized that this was due to an interaction between personality and environment. Specifically, we argued that in cooperation-friendly environments - given certain beliefs-defection is more risky than cooperation. The main reason for this is that, in such a situation, defection potentially yields outcomes of higher variance (and vice versa, for cooperation-unfriendly environments). In line with this hypothesis, we showed, in two experiments and a reanalysis of a study by Fudenberg, Rand, and Dreber (American Economic Review, in press), that the degree of cooperation increases with dispositional risk aversion in cooperation-friendly environments, but not in cooperation-unfriendly environments. We also found similar person-situation interactions for neuroticism and extraversion.
\end{abstract}

Keywords Social dilemma · Decision making $\cdot$ Prisoner's dilemma $\cdot$ Risk aversion $\cdot$ Individual differences $\cdot$ Personality

Cooperation is crucial for efficient interactions in societies. However, many situations entail a dilemma structure, in that

Electronic supplementary material The online version of this article (doi:10.3758/s13423-012-0224-z) contains supplementary material, which is available to authorized users.

A. Glöckner $(\bowtie) \cdot$ B. E. Hilbig

Max Planck Institute for Research on Collective Goods,

Kurt-Schumacher-Str. 10,

D-53113 Bonn, Germany

e-mail: gloeckner@coll.mpg.de

B. E. Hilbig

School of Social Sciences, University of Mannheim,

Schloss Ehrenhof Ost,

D-68131 Mannheim, Germany noncooperative behavior is individually more beneficial than cooperation, as in the classic prisoner's dilemma (PD; Rapoport \& Chammah, 1965). Behavior in PDs has been extensively studied, and substantial cooperation rates have been observed, contrary to rational-choice predictions (cf. Colman, 2003; Moshagen, Hilbig, \& Musch, 2011). In a meta-analysis of 37 studies, the degrees of cooperation ranged from $5 \%$ to $96.9 \%$, with an average of $47.4 \%$ (Sally, 1995). According to the same analysis, the degree of cooperation depends on a multitude of situational factors. In particular, the specific structure of the payoff matrix has a strong influence, such that a lower temptation to defect and smaller losses when being exploited-as expressed in the cooperation index (Rapoport \& Chammah, 1965)-increase cooperation (Vlaev \& Chater, 2006).

Cooperation is observed not only in one-shot games, but also - and more so - in finitely repeated PD games (Andreoni $\&$ Miller, 1993). This seems plausible, as actors should weigh the potential long-term benefit of mutual cooperation against short-term profit maximization. Indeed, under certain circumstances, it may well feel riskier to exploit others, given that one will interact with them again and must thus fear retaliation through subsequent noncooperation. Similarly, in a finitely repeated PD, uncertainty about the partners' strategy can render cooperation rational - at least up to a certain round (Kreps, Milgrom, \& Wilson, 1982). This situation holds if the other player is assumed not to be strictly rational, but rather a tit-for-tat player type (i.e., starting with cooperation and then responding with the same behavior observed in the other player). The number of rounds in which a rational player will cooperate is thus a function of the subjective probability of the other playing tit-for-tat and of the payoffs in the PD.

In contrast to the well-explored effects of situational factors, relatively little systematic research has been conducted on the influence of personality factors in PDs. Sally 
(1995) found that psychology students tended to cooperate more than other participants did. Furthermore, it has been found that an internal locus of control, high self-monitoring, and high sensation seeking were systematically associated with cooperative behavior, particularly in repeated PDs (Boone et al., 2002; Boone, De Brabander, \& van Witteloostuijn, 1999).

In the present work, we focus on the effects of individual differences in probabilistic risk aversion on cooperation. Risk aversion captures an individual's dispositional tendency to evaluate a prospect with (positive) probabilistic outcomes as having a value lower than (i.e., risk aversion), equal to (i.e., risk neutrality), or higher than (i.e., risk seeking) its expected value. Probabilistic risk aversion can be measured using binary decisions between safe and risky options (Holt \& Laury, 2002). Note, however, that we are not concerned with what has been called strategic uncertainty - that is, uncertainty about the other player's behavior in equilibrium, due to missing information about that player's payoff (Morris \& Shin, 2003). Rather, we refer to uncertain beliefs concerning the other's strategy such that the PD translates into choices between options that differ in risk. As we will argue in more detail below, the relationship between probabilistic risk aversion and PD cooperation is likely to depend on the payoff structure, thus leading to a person-situation interaction that constitutes our main hypothesis.

So far, some researchers have reported negative correlations between probabilistic risk aversion and cooperation in a PD: Dolbear and Lave (1966) found a small, and nonsignificant, negative correlation in an environment with an average cooperation rate of $31 \%$. Similarly, de Heus, Hoogervorst, and van Dijk (2010) found a slightly negative and nonsignificant correlation in a one-shot PD with an average cooperation rate of 53\% (using a questionnaire measure of risk aversion). Sabater-Grande and Georgantzis (2002) reported a significant negative correlation in an environment with an average cooperation rate of $47 \% .{ }^{1}$ Thus, all three studies were conducted in environments with intermediate to low average cooperation rates. We hypothesize that the relation between risk aversion and cooperation reverses in environments with high cooperation rates, because defection would lead to higher variability of outcomes in such environments, and risk aversion would imply trying to avoid the subjective risk inherent in such variability.

\section{Risk aversion and cooperation in different environments}

Assume a PD with Players A and B choosing between Actions 1 (to cooperate) and 2 (to defect) and with symmetric payoffs

\footnotetext{
${ }^{1}$ Related to this inconclusive finding, Eckel and Wilson (2004) also found no significant influence of risk aversion on behavior in a trust game.
}

denoted C (both cooperate), D (both defect), $\mathrm{T}$ (temptation payoff: A defects, B cooperates), and $\mathrm{S}$ (sucker payoff: A cooperates, $\mathrm{B}$ defects), with $\mathrm{T}>\mathrm{C}>\mathrm{D}>\mathrm{S}$ and $\mathrm{C}>$ $(\mathrm{T}+\mathrm{S}) / 2$. The cooperation index CI (Rapoport \& Chammah, $1965)$ is defined as the ratio $(C-D) /(T-S)$, with larger values implying that defection will be less tempting and cooperation less risky. As such, the CI can be taken as a measure of how cooperation-friendly an environment is.

In cooperation-unfriendly environments, both players will mainly expect defection from the other player. In this case, defection will ensure a stable (albeit relatively low) outcome and avoid variability in the form of potential fluctuations in high (C) and low (S) outcomes. Defection will be used to defend oneself from being exploited. In other words, defection is the safe option, and thus more appealing to individuals high in risk aversion. In such a cooperationunfriendly environment, risk aversion and cooperation would thus be negatively related, as has been indicated by prior research (Sabater-Grande \& Georgantzis, 2002).

However, in cooperation-friendly environments, a different picture should emerge: Both players will predominantly expect cooperation; consequently, over several rounds, a constant payoff of $\mathrm{C}$ is possible. Defection would represent a violation of the other player's expectation (i.e., an implicit norm). In this case, although defection would produce one high outcome $(\mathrm{T})$, the subsequent consequence would be one or more low outcomes (D or S), due to retaliation. Hence, the variability of outcomes will be higher for defection than for cooperation, and risk-averse individuals should be more likely to prefer the "safe option", and thus cooperate. In such environments, risk seekers might resort to defection in order to exploit the other - given that the other is expected to cooperate.

A mechanism similar to the one suggested for cooperationfriendly environments was recently pointed out by Hirsh and Peterson (2009), who investigated the link between Big-5 personality traits (i.e., neuroticism, openness to experience, extraversion, conscientiousness, and agreeableness; see, e.g., McCrae \& Costa, 1999) and cooperation in repeated PDs. They observed that the withdrawal aspect of neuroticism positively predicted cooperation, as did the enthusiasm aspect of extraversion. On the basis of these findings, Hirsh and Peterson speculated that there might be multiple pathways to cooperation in the PD: one based on fear of punishment (related to neuroticism), and the other based on the rewarding aspects of cooperation (related to extraversion). The former clearly hints that risk aversion, or more generally speaking, a tendency to be fearful, need not necessarily yield less cooperation. Rather, the outcome may depend on the situation in a predictable way.

In the following study, we further dissect the link between dispositional risk aversion and cooperation. As sketched above, players in a repeated PD encounter different 
risks that they might aim to avoid. According to SabaterGrande and Georgantzis (2002), they could try to avoid the risk of being the sucker, thus playing the Nash equilibrium (defect) in order to be immune to exploitation. However, in line with our prediction and with the argument of Hirsh and Peterson (2009), players in a partner design might also fear being punished for defection in subsequent rounds. Overall, the influence of dispositional factors may thus depend on the situation, and in particular on the degree of cooperativeness this situation brings about (see, e.g., Hilbig \& Zettler, 2009).

In the first experiment, we aimed to qualify the findings of Sabater-Grande and Georgantzis (2002) by showing that under specific cooperation-friendly conditions - namely, repeated PDs using a partner design and comprising relatively low sucker payoffs - cooperation will be easily established as the predominant behavior, and that cooperation rates will thus increase with risk aversion. We thus understood the fear of risk-averse individuals as being relative to the situation and the behavior that this situation pervasively induces: If the environment is hostile to cooperation, the risk-averse will particularly fear being exploited and thus defect, as shown by Sabater-Grande and Georgantzis. If, by contrast, cooperation is the predominant behavior in a given situation, risk-averse individuals will fear being punished for defecting, and thus maintain cooperation. We first aimed to demonstrate the latter hypothesis.

\section{Experiment 1: Cooperation-friendly environment}

Method

\section{Participants and design}

A group of 96 students from the University of Bonn took part in the experiment ( 41 female, 55 male; mean age 24.3 years). The experiment lasted about $90 \mathrm{~min}$. Participants were recruited from the EconLab participant pool using ORSEE (Greiner, 2004). The experiment was run on z-Tree (Fischbacher, 2007). Participants received a performancecontingent payment for the study, yielding payoffs between $€ 9.20$ and $€ 14.80$ (approx. USD13-21). The experiment was hence incentivized, and there was no deception involved, nor had participants previously taken part in experiments involving deception.

\section{Materials}

Risk aversion measure We applied a standard procedure to measure participants' risk preferences, using incentivized decisions between gambles (Holt \& Laury, 2002). In this procedure, participants make 10 binary choices between pairs of gambles: a safe gamble that has two medium outcomes (i.e., in $x$ out of 10 cases, you win $€ 2$; otherwise, you win $€ 1.60)$ and a risky gamble that has a high and a low outcome (i.e., in $x$ out of 10 cases, you win $€ 3.85$; otherwise, you win $€ 0.10$ ). Over the 10 decisions, the likelihood of winning the higher outcome in both gambles increases by simultaneously increasing $x$ from 1 to 10 for both gambles. As the relative attractiveness of the risky option increases with $x$, the number of choices for the safe gamble is an indicator of an individual's risk aversion, with high numbers indicating high risk aversion (scores range from 0 to 10 , with 4 indicating risk neutrality). For each participant, one decision is randomly selected, the gamble is played, and the win is added to the overall payment.

Repeated PD game We implemented a computer-based PD with the payoff structure given in Table 1, which we anticipated would induce a high cooperation rate. We used a partner design with an informed restart after 20 rounds. Hence, participants were randomly assigned to dyads, playing together for 20 rounds. After the first 20 rounds, new dyads were randomly formed to play the remaining 20 rounds. Players were completely informed about the payoff structure of the game, were anonymous to each other, and could not communicate during the experiment. The two decision alternatives were named "1," for cooperation, and "2," for defection. The exchange rate for the participants' payments was 1,500 points $=€ 1$. After each decision, participants' beliefs about the other's behavior were elicited (i.e., "What do you predict the other will have chosen?"). We made this belief elicitation incentive-compatible, as participants had to bet between 1 and 49 of their own points

Table 1 Payoff table in the prisoner's dilemma games investigated in Experiments 1 and 2

\begin{tabular}{|c|c|c|c|}
\hline & & \multicolumn{2}{|l|}{ Player 2} \\
\hline & & 1 (Cooperate) & 2 (Defect) \\
\hline \multirow[t]{10}{*}{ Player 1} & 1 (Cooperate) & Experiment 1 & 50,300 \\
\hline & & 200,200 & \\
\hline & & Experiment 2 & \\
\hline & & CI high: 285, 285 & \\
\hline & & CI low: 185,185 & \\
\hline & 2 (Defect) & 300,50 & Experiment 1 \\
\hline & & & 100,100 \\
\hline & & & Experiment 2 \\
\hline & & & CI high: 60,60 \\
\hline & & & CI low: 160,160 \\
\hline
\end{tabular}

The first and second numbers in each cell refer to the payoffs for Players 1 and 2. CI high and CI low refer to the conditions with a high versus a low cooperation index 
on the belief. This sum was lost if they were wrong and was added to their earnings if they were right.

\section{Results and discussion}

In line with previous findings, we observed that participants were generally risk-averse and differed considerably in their risk preferences $(M=5.63, S D=2.00)$. We also observed a generally high cooperation rate of about $70 \%$ in the first 20 rounds, and an even higher cooperation rate after the restart in Round 21. Hence, as intended, we were successful in establishing pervasive cooperation by providing a cooperationfriendly environment. In line with our main hypothesis, the average cooperation rate per individual was positively correlated with risk aversion at a modest level, $r=.21, p=.04$ $(N=96 ; 95 \%$ confidence interval $=.01-.39)$.

A logistic regression with cooperation as the dependent variable and risk aversion score as a predictor - correcting for dependencies over time and within dyads by clustering at the level of dyads and including period dummies to account for time effects - confirmed this conclusion, odds ratio $=1.16, z=2.44, p=.015$ (Fig. 1). This was further supported by a multilevel random-effects model estimating random intercepts for subjects and dyads (with subjects nested in dyads), odds ratio $=1.09, z=1.81, p=.072$. This effect was mainly driven by differences in the middle rounds (Fig. 2). Differences in cooperation appeared after the interaction was established and before anticipation of the interaction ending soon (i.e., the classic end-round effect). After the restart, the effect of risk aversion was somewhat smaller in magnitude.

To shed light on the mechanisms driving the effect of risk aversion, we further analyzed behavior conditional on participants' beliefs concerning the cooperation of the other player. If our above arguments hold, risk seekers should

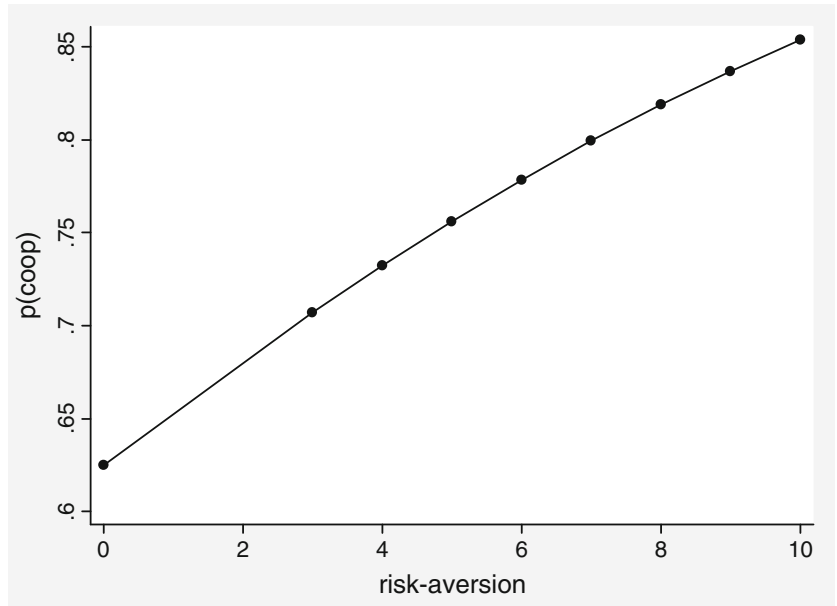

Fig. 1 Cooperation as a function of risk aversion in Experiment 1. On the $y$-axis, $p$ (coop) indicates the predicted probability of cooperation, controlling for the effect of rounds

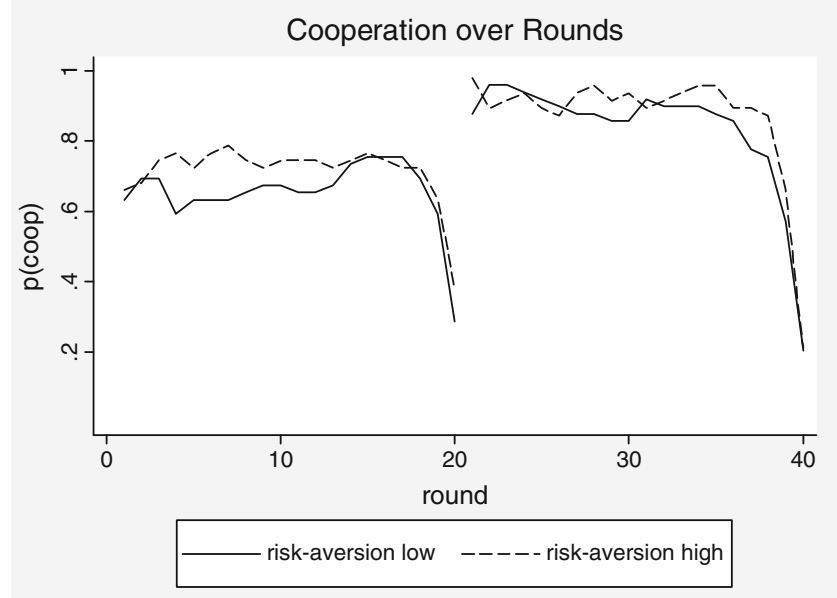

Fig. 2 Development of cooperation over rounds in Experiment 1. A median split was used for the classification of high versus low risk aversion

try to exploit the opponent when they expect him or her to cooperate. Rerunning the above-reported clustercorrected logistic regression, conditional upon different beliefs, indeed corroborated that the effect of risk aversion on cooperation was only found when players expected the other to cooperate, odds ratio $=1.26$, $z=2.61, p=.009$, but not for situations in which defection was expected, $p>.31$.

In contrast to previous findings (Sabater-Grande \& Georgantzis, 2002), our results showed that risk aversion does not necessarily yield defection in the PD. On the contrary, we found that cooperation increases with risk aversion in an environment that promotes cooperation. However, other differences between our study and that of Sabater-Grande and Georgantzis might have been responsible for the different results we obtained. Thus, to strengthen our interpretation, we conducted a second experiment in which we manipulated the likelihood of cooperation in the environment via the payoff matrix.

\section{Experiment 2: Manipulation of the cooperation index}

To provide more conclusive evidence for the hypothesis that the link between risk aversion and cooperation is moderated by the degree to which the environment fosters cooperation, we experimentally varied the cooperation index (CI) in this experiment. To further strengthen cross-experiment comparisons, we also included a measure of Big-5 personality traits to investigate whether the previously observed effects of neuroticism and extraversion on cooperation (Hirsh \& Peterson, 2009) are also qualified by the interactions between these factors and the CI. 
Method

\section{Participants and design}

A group of 73 students from the University of Bonn took part in this experiment (31 female, 42 male; mean age 22.8 years). The participants were recruited from the Max Planck Institute Decision Lab participant pool using ORSEE (Greiner, 2004). The experiment was run on the BoXS software (Seithe, 2010) and consisted of an online questionnaire and a lab session. The online questionnaire contained the risk aversion measure and the German version of the 60item NEO-FFI personality scale (Borkenau \& Ostendorf, 1993). This questionnaire was administered one day before the experimental session, to separate the assessment of dispositional factors from the experiment itself, thus reducing the danger of dependencies (for similar arguments, see Hilbig, Zettler, \& Heydasch, 2011).

\section{Materials and procedure}

As in the first experiment, the participants played a computer-based PD for 20 rounds with the same partner. In the previous study, the CI was .4. In the present experiment, we used the same $\mathrm{T}$ and $\mathrm{S}$ payoffs but manipulated the $\mathrm{C}$ and $\mathrm{D}$ payoffs between participants, such that the CI was either .1 or .9 (see Table 1). We thus created CI-high and CI-low conditions that would mirror cooperation-friendly and -hostile environments, respectively, and predicted that the CI condition would moderate the link between risk aversion and cooperation. The risk aversion measure and the belief elicitation were incentivized in the same way as before.

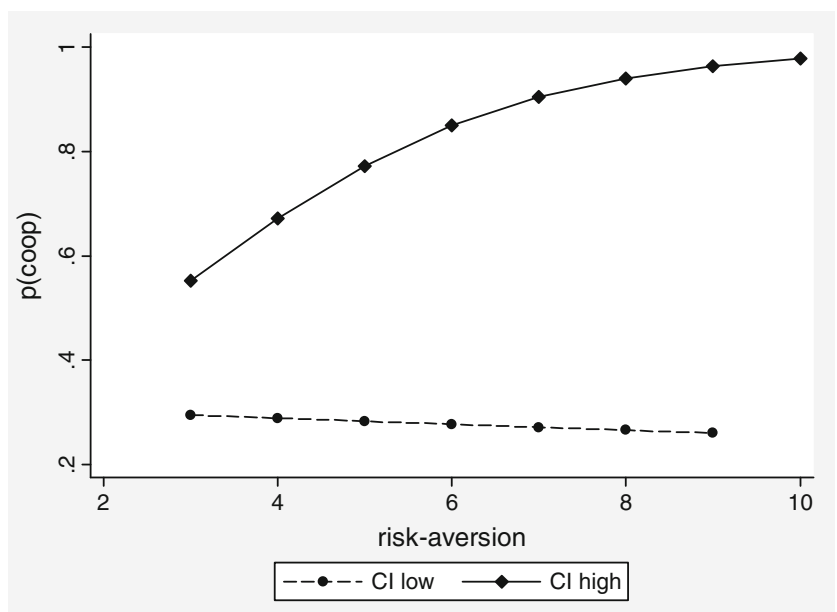

Fig. 3 Cooperation as a function of risk aversion in Experiment 2. On the $y$-axis, $p$ (coop) indicates the predicted probability of cooperation, controlling for the effect of rounds. CI, cooperation index

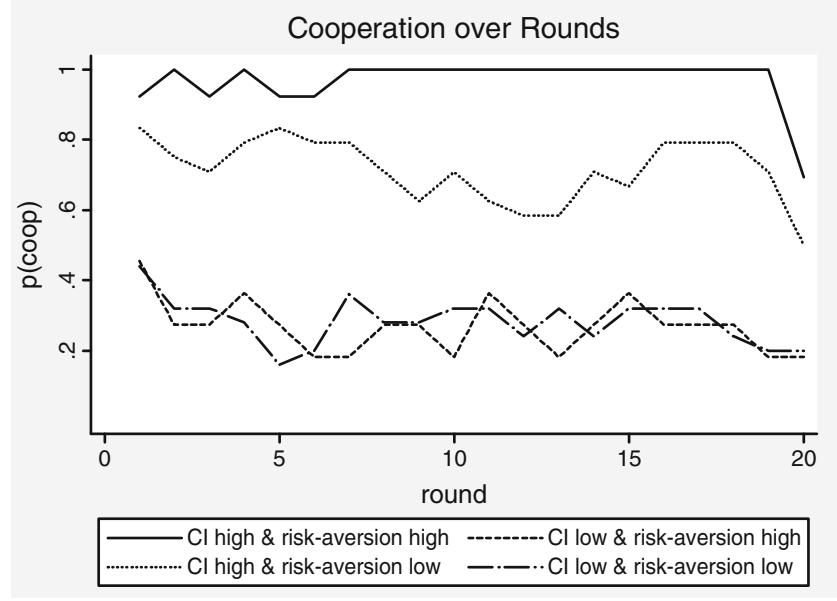

Fig. 4 Cooperation over rounds in Experiment 2. CI, cooperation index

Results and discussion

We were successful in inducing different cooperation rates, as cooperation was substantial $(M=.80, S E=.05)$ in the CIhigh condition and significantly lower $(M=.28, S E=.05)$ in the CI-low condition, $t(71)=7.31, p<.001$. Risk preferences again showed variability and a tendency toward risk aversion $(M=5.72, S D=1.61)$. The personality scales for neuroticism (Cronbach's $\alpha=.89$ ) and extraversion (Cronbach's $\alpha=.82$ ) were reliable and had sufficient variance.

Table 2 Logistic regression predicting cooperation in Experiment 2

\begin{tabular}{ll}
\hline Factor & $\begin{array}{l}\text { Cooperation } \\
(1=y e s)\end{array}$ \\
\hline Cooperation index $(\mathrm{CI})$ high & $16.38^{* * *}$ \\
$(1=y e s, 0=n o)$ & $(6.52)$ \\
Neuroticism & 0.806 \\
Neuroticism $\times$ CI & $(-0.64)$ \\
& $4.527^{*}$ \\
Risk aversion & $(2.23)$ \\
Risk aversion $\times$ CI & $1.292^{*}$ \\
Extraversion & $(2.21)$ \\
& $1.883^{* *}$ \\
Extraversion $\times$ CI & $(2.72)$ \\
$N$ & 0.975 \\
pseudo- $R^{2}$ & $(-0.06)$ \\
\hline
\end{tabular}

The coefficients are odds ratios, with $z$ statistics given in parentheses. Standard errors were corrected for 73 clusters in the observations, and round dummies are omitted. ${ }^{*} p<.05 .{ }^{* *} p<.01 .{ }^{* * *} p<.001$ 

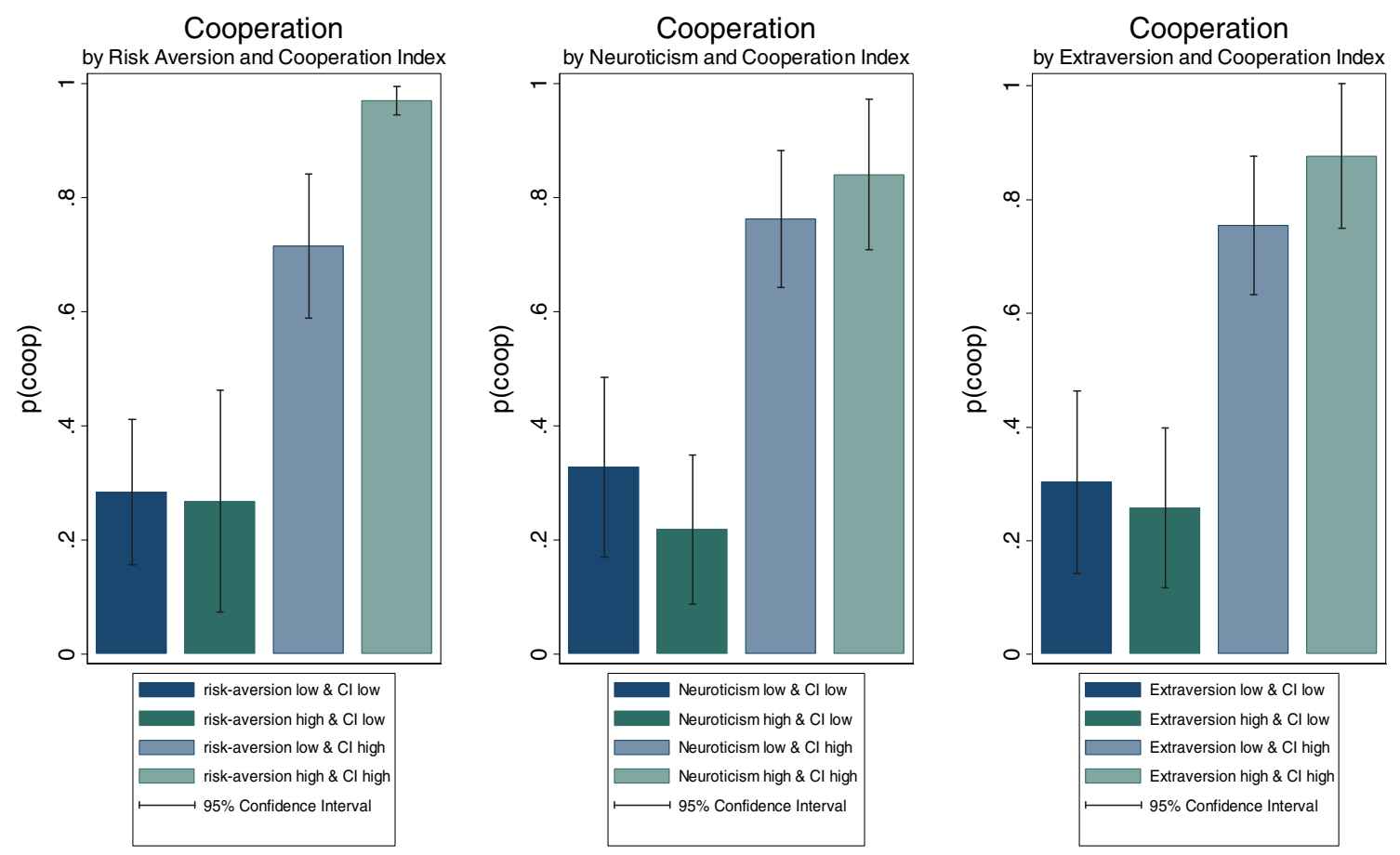

Fig. 5 Factors influencing cooperation in Experiment 2. Median splits were used for classification of high versus low risk aversion, neuroticism, and extraversion. Standard errors are corrected for clusters in the observations. CI, cooperation index

In line with our main hypothesis, cooperation increased with risk aversion in the CI-high condition, $r=.41, p=.01$, but not in the CI-low condition, $r=-.03, p=.88$. The correlations differed significantly, $z=1.93, p=.028$, thus supporting our interaction hypothesis (Fig. 3). To check the stability of this finding, we conducted a logistic regression predicting cooperation as a function of the main effects of condition and risk aversion score (both variables centered) and of their interaction (again clustering at the dyad level and including period dummies). In line with the aggregate analysis, the interaction term was significant, odds ratio $=1.73, z=2.36, p=.018$; this also held in an equivalent multilevel regression with random effects for dyads and participants nested in dyads, odds ratio $=2.69, z=2.05, p=.041$. In the CI-high condition, risk-averse individuals cooperated more than did their less risk-averse counterparts on all trials, whereas in the CI-low condition, the pattern was mixed (Fig. 4).

When we also included effects of neuroticism and extraversion, as well as their respective interactions, with condition (CI-high vs. CI-low) in the regression, all three interactions turned out to be significant (Table 2). The previously observed positive predictions of cooperation from neuroticism and extraversion held only in the highcooperation environment and reversed in the lowcooperation environment (Fig. 5). ${ }^{2}$ This effect was found

\footnotetext{
${ }^{2}$ Hirsh and Peterson (2009) do not report the payoffs of their PD, which would have allowed for calculating a CI, but they observed a cooperation rate that was between the rates in our two conditions.
}

although - in line with previous findings (e.g., Richardson, 1968) - neuroticism and extraversion were negatively correlated $(r=-.52, p<.001)$. A closer look at the data revealed that the interaction for extraversion turned out to be significant only if neuroticism was controlled for, which indicates an interesting suppression effect. Hence, the nonshared aspects of both factors seem to drive the effect on cooperation. Note that no other Big-5 factor predicted cooperation or interacted with the CI condition. Risk aversion, however, did show interesting and theoretically plausible links to Big-5 factors, as it was positively related to neuroticism $(r=.20, p=.09)$, but negatively related to openness to experience $(r=-.30, p=.01)$ and extraversion $(r=-.21$, $p=.08)$.

Finally, we again analyzed cooperation rates conditional on participants' beliefs concerning the other's behavior. In the CI-high condition, we replicated the finding that risk aversion positively predicts cooperation only when the other is expected to cooperate, odds ratio $=1.58, z=2.24, p=.025$, but not when defection is expected $(p>.25)$. For the CI-low condition, we found no effects for either of the belief options $(p>.88)$. In the first round and prior to any interaction, the proportion of individuals expecting the other to cooperate was significantly higher in the CI-high (.84) than in the CI-low (.53) condition, $z=$ $2.85, p<.01$. One interesting further finding was that individuals high in risk aversion responded with more cooperation to partners' defection in the previous round than did those low in risk aversion, thus indicating that the former tended to 
be more forgiving. This pattern, however, reversed given two consecutive defections of the partner (see the online supplement for details).

\section{Secondary analysis of the data set by Fudenberg, Rand, and Dreber (in press)}

To further test the stability and independence of our findings, we conducted a secondary analysis of the data set reported by Fudenberg, Rand, and Dreber (in press). ${ }^{3}$ Summarized briefly (further details may be found in the supplementary materials), we regressed cooperation rates on CI, individuals' scores on a subjective risk aversion measure, and the interaction of these factors. The interaction turned out to be significant and in the expected direction, corroborating the results from Experiments 1 and 2. Separate regressions for the highest and lowest CI conditions revealed that cooperation increased significantly with risk aversion in the former but decreased significantly in the latter condition (all $p \mathrm{~s}<.05$ ).

\section{General discussion}

In repeated prisoner's dilemma games, people run different risks: They might be exploited if they cooperate, or they might subsequently be punished through consistent noncooperation once they defect. Supporting the prevalence of the former effect, it has been shown that cooperation is negatively linked to individual tendencies toward risk aversion, even in PD situations with repeated play (Sabater-Grande \& Georgantzis, 2002). Herein, we qualified these findings in two experiments and one reanalysis, showing that individuals instead try to avoid the risk they would run through defection once the environment is cooperation-friendly. Specifically, the tendency to cooperate increased with increasing dispositional risk aversion in such situations.

Furthermore, our results yielded similar interactions for personality factors such as neuroticism and extraversion, thus qualifying previous findings concerning the relationship between personality and cooperation (Hirsh \& Peterson, 2009). Because the interaction pattern of neuroticism mirrored the risk aversion findings-and given the strong conceptual links between the two- the same explanation could be used for the effect of neuroticism in the PD (avoiding the risk inherent in deviating from the norm). However, the interaction for extraversion was not predicted a priori. Replications and further investigations of the facets driving this interaction will be needed before sound conclusions can be drawn concerning this effect.

\footnotetext{
${ }^{3}$ We are grateful to the authors for granting us access to this data set.
}

One important limitation of our findings is that, in all three data sets considered herein, the cooperation level was manipulated by means of changing the payoff structure (i.e., the CI index). Hence, it necessarily remains an open question whether the observed interaction effect was due directly to the changes in payoffs or was mediated by different beliefs concerning cooperation. To tease such explanations apart, further investigations should be conducted in which cooperation is manipulated in alternative ways.

Overall, our findings indicate that the relation between personality factors and cooperation in strategic games is complex. As such, relations appear to depend heavily on the specific properties of the strategic situation (cf. Hilbig \& Zettler, 2009; Zettler \& Hilbig, 2010), which can induce different beliefs. Simple mechanisms, such as risk aversion stimulating defection (Sabater-Grande \& Georgantzis, 2002), seem to be limited to certain circumstances. Further qualifying such previous findings, we have shown theoretically and empirically that risk aversion can also boost cooperation if the environment is cooperation-friendly, so that cooperation is the predominant and expected behavior. Here, risk-averse decision makers need not fear being exploited, but have good reason to fear being punished by their partners for defection. Stated differently, risk aversion seems to prevent deviating from the pervasive behaviorthat is, the tendency most strongly implied by the given situation. In sum, the present work is in line with recent calls for investigating individual differences in decision making in terms of person-situation interactions (Appelt, Milch, Handgraaf, \& Weber, 2011), and it enhances our understanding of both who cooperates in social dilemmas and when.

\section{References}

Andreoni, J., \& Miller, J. H. (1993). Rational cooperation in the finitely repeated prisoner's dilemma: Experimental evidence. The Economic Journal, 103, 570-585.

Appelt, K. C., Milch, K. F., Handgraaf, M. J. J., \& Weber, E. U. (2011). The Decision Making Individual Differences Inventory and guidelines for the study of individual differences in judgment and decision-making research. Judgment and Decision Making, 6, 252-262.

Boone, C., De Brabander, B., Carree, M., de Jong, G., van Olffen, W., \& van Witteloostuijn, A. (2002). Locus of control and learning to cooperate in a prisoner's dilemma game. Personality and Individual Differences, 32, 929-946. doi:10.1016/S0191-8869(01)00100-3

Boone, C., De Brabander, B., \& van Witteloostuijn, A. (1999). The impact of personality on behavior in five Prisoner's Dilemma games. Journal of Economic Psychology, 20, 343-377.

Borkenau, P., \& Ostendorf, F. (1993). NEO-Fünf-Faktoren Inventar (NEO-FFI) nach Costa und McCrae: Handanweisung. Göttingen: Hogrefe.

Colman, A. M. (2003). Cooperation, psychological game theory, and limitations of rationality in social interaction. The Behavioral and Brain Sciences, 26, 139-198. doi:10.1017/S0140525X03000050 
de Heus, P., Hoogervorst, N., \& van Dijk, E. (2010). Framing prisoners and chickens: Valence effects in the prisoner's dilemma and the chicken game. Journal of Experimental Social Psychology, 46, 736-742.

Dolbear, F. T., Jr., \& Lave, L. B. (1966). Risk orientation as a predictor in the prisoner's dilemma. Journal of Conflict Resolution, 10, 506-515.

Eckel, C. C., \& Wilson, R. K. (2004). Is trust a risky decision? Journal of Economic Behavior and Organization, 55, 447-465.

Fischbacher, U. (2007). z-Tree: Zurich toolbox for ready-made economic experiments. Experimental Economics, 10, 171-178.

Fudenberg, D., Rand, D. G., \& Dreber, A. (in press). Slow to anger and fast to forget: Cooperation in an uncertain world. American Economic Review

Greiner, B. (2004). An online recruitment system for economic experiments. In K. Kremer \& V. Macho (Eds.), Forschung und wissenschaftliches Rechnen 2003, GWDG Bericht 63 (pp. 79-93). Göttingen: Gesellschaft für Wissenschaftliche Datenverarbeitung.

Hilbig, B. E., \& Zettler, I. (2009). Pillars of cooperation: Honestyhumility, social value orientations, and economic behavior. Journal of Research in Personality, 43, 516-519.

Hilbig, B. E., Zettler, I., \& Heydasch, T. (2011). Personality, punishment and public goods: Strategic shifts towards cooperation as a matter of dispositional honesty-humility. European Journal of Personality. Advance online publication. doi:10.1002/per.830

Hirsh, J. B., \& Peterson, J. B. (2009). Extraversion, neuroticism, and the prisoner's dilemma. Personality and Individual Differences, 46, 254-256. doi:10.1016/j.paid.2008.10.006

Holt, C. A., \& Laury, S. K. (2002). Risk aversion and incentive effects. American Economic Review, 92, 1644-1655.

Kreps, D. M., Milgrom, P., \& Wilson, J. R. R. (1982). Rational cooperation in the repeated prisoner's dilemma Journal of Economic Theory, 27, 245-252.
McCrae, R. R., \& Costa, P. T., Jr. (1999). A five-factor theory of personality. In L. A. Pervin \& O. P. John (Eds.), Handbook of personality: Theory and research (2nd ed., pp. 139-153). New York, NY: Guilford Press.

Morris, S., \& Shin, H. S. (2003). Global games: theory and applications. In M. Dewatripont, L. Hansen, \& S. Turnovsky (Eds.), Advances in Economics and Econometrics, the Eighth World Congress (Vol. 1, pp. 56-114). Cambridge, U.K.: Cambridge University Press.

Moshagen, M., Hilbig, B. E., \& Musch, J. (2011). Defection in the dark? A randomized-response investigation of cooperativeness in social dilemma games. European Journal of Social Psychology, 41, 638-644. doi:10.1002/ejsp.793

Rapoport, A., \& Chammah, A. M. (1965). Prisoner's dilemma. Ann Arbor, MI: University of Michigan Press.

Richardson, J. F. (1968). Correlations between the extraversion and neuroticism scales of the EPI. Australian Journal of Psychology, 20, 15-18.

Sabater-Grande, G., \& Georgantzis, N. (2002). Accounting for risk aversion in repeated prisoners' dilemma games: An experimental test. Journal of Economic Behavior and Organization, 48, 37-50.

Sally, D. (1995). Conversation and cooperation in social dilemmas: A meta-analysis of experiments from 1958 to 1992. Rationality and Society, 7, 58-92.

Seithe, M. (2010). Introducing the Bonn Experiment System (Discussion paper). Bonn, Germany: Graduate School of Economics, University of Bonn. Available at http://boxs.uni-bonn.de/boxs.pdf

Vlaev, I., \& Chater, N. (2006). Game relativity: How context influences strategic decision making. Journal of Experimental Psychology: Learning, Memory, and Cognition, 32, 131-149.

Zettler, I., \& Hilbig, B. E. (2010). Honesty-humility and a personsituation interaction at work. European Journal of Personality, $24,569-582$. 